\title{
Exploring Qualitative Displays and Interfaces
}

\author{
Dan Lockton \\ Imaginaries Lab \\ School of Design \\ Carnegie Mellon University \\ Pittsburgh, PA 15213, USA \\ danlockton@cmu.edu \\ Delanie Ricketts \\ Imaginaries Lab \\ School of Design \\ Carnegie Mellon University \\ Pittsburgh, PA 15213, USA \\ dmricket@andrew.cmu.edu
}

\author{
Shruti Aditya Chowdhury \\ Imaginaries Lab \\ School of Design \\ Carnegie Mellon University \\ Pittsburgh, PA 15213, USA \\ sadityac@andrew.cmu.edu

\section{Chang Hee Lee} \\ Innovation Design Engineering \\ School of Design \\ Royal College of Art \\ London, SW7 2EU, UK \\ changhee.lee@network.rca.ac.uk
}

\section{This is the author's version of the work. It is posted here for your personal use. The definitive Version of Record will be published by ACM at: http://dx.doi.org/10.1145/3027063.3053165}

Permission to make digital or hard copies of part or all of this work for personal or classroom use is granted without fee provided that copies are not made or distributed for profit or commercial advantage and that copies bear this notice and the full citation on the first page. Copyrights for third-party components of this work must be honoured. For all other uses, contact the Owner/Author.

Copyright is held by the owner/author(s)

CHI'17 Extended Abstracts, May 06-11, 2017, Denver, CO, USA ACM 978-1-4503-4656-6/17/05.

http://dx.doi.org/10.1145/3027063.3053165

\begin{abstract}
Much of how we construct meaning in the real world is qualitative rather than quantitative. We think and act in response to, and in dialogue with, qualities of phenomena, and relationships between them. Yet, quantification has become a default mode for information display, and for interfaces supporting decision-making and behaviour change. There are more opportunities within $\mathrm{HCI}$ for qualitative displays and interfaces, for information presentation, and an aid to help people explore their own thinking and relationships with ideas. Here we attempt one dimension of a tentative classification to support projects exploring opportunities for qualitative displays within design.
\end{abstract}

\section{Author Keywords}

Interaction design; Qualitative interfaces and displays; Analog computing; Understanding.

\section{ACM Classification Keywords}

H.5.m. Information interfaces and presentation (e.g., $\mathrm{HCI}$ ): Miscellaneous.

\section{Introduction}

Outside of the digital, we largely live and think and act and feel in response to, and in dialogue with, the perceived qualities of people, things and phenomena, and the relationships between them, rather than their 


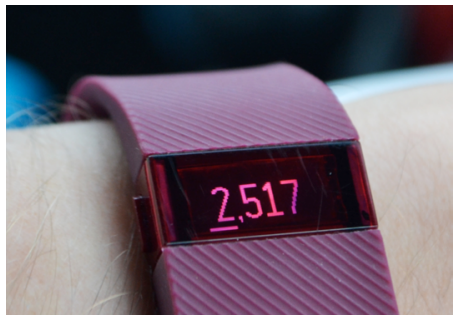

Figure 1: A typical form of quantitative interface: a Fitbit's display of number of steps taken.

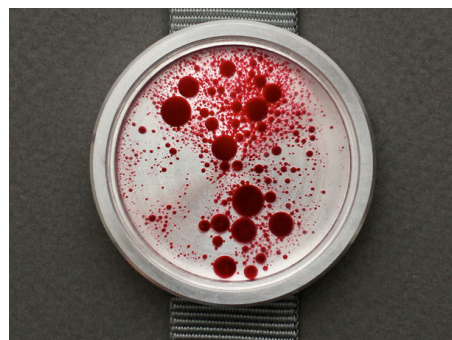

Figure 2: The Emulsion activity tracker, by Norwegian design studio Skrekkøgle, contains two immiscible liquids. Movement splits the colored liquid into smaller drops, making patterns (Photo used with permission of Skrekkøgle).

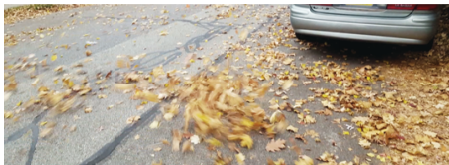

Figure 3: Leaves blowing around can be thought of as a form of qualitative display for the wind. number. Much of our experience of-and meaningmaking in-the real world is qualitative rather than quantitative. How friendly was she? How tired do I feel right now? Who's the tallest in the group? How windy is it out there? Which route shall we take to work? How was your meal? Which apple looks tastier? Which piece of music best suits the mood? Do I need to use the bathroom? Particularly rarely do we deal with quantities in relation to abstract concepts-two coffees, half a biscuit, three children, but rarely 0.5 loves or 6.8 sadnesses. And yet, quantification has become the default mode of interaction with technology, of display of information, and of interfaces which aim to support decision-making and behaviour change in everyday life [27]. We need not elaborate here the phenomena of the quantified self $[36,42]$ and personal informatics more widely $[24,12]$, except to note the prevalence of numerical approaches (Figure 1) and the relative unusualness of non-numerical, pattern-based forms (Figure 2). But what might we be missing through this focus on quantification? It seems as though there might be opportunities for HCI to explore forms of qualitative display and interface, as an approach to information presentation and interaction, as an aid to help people explore their own and each other's thinking, and specifically to help people understand their relationships and agency with systems. In this article we discuss qualitative displays and interfaces, and attempt one dimension of a tentative classification supporting design projects exploring this space.

\section{What could qualitative displays and}

\section{interfaces be?}

Here we define a qualitative display as being a way in which information is presented primarily through representing qualities of phenomena; a qualitative interface enables people to interact with a system through responding to or creating these qualities. 'Displays' are not necessarily solely visual-obvious to say, perhaps, but not always made explicit. Before exploring some examples, we will look at some theoretical issues. The terms 'qualitative interface' or 'qualitative display' are not commonly used outside of some introductory human factors textbooks, but forms of interface along these lines are found in lots of projects at CHI, TEI, DIS, Ubicomp and other venues, without authors explicitly drawing our attention to the concept-it is perhaps just too obvious and too broad to merit specific comment in $\mathrm{HCI}$ and interaction design research. But, assuming the idea does have value, what are some characteristics?

A human face is a qualitative interface, perhaps the earliest we encounter [e.g. 40] along with the voice. We learn to read and interpret emotions in others' expressions, to recognize commonalities and differences across people, to make inferences about internal and external factors affecting the person, and monitor the effects we or others are having on that person. We understand that the face and voice and our ability to read them are abstractions, interpretations, not perfect knowledge, but a model which enables us to make decisions in conjunction with our reading of our own emotions. In a sense, the whole world, as we perceive it, is a very complex qualitative interface. The most accurate model of a phenomenon is the phenomenon itself, but it is only useful to us to the extent we can understand what we are observing, detect the patterns we need to, and recognize that we are constructing the 'reality' we perceive. We are always creating a model [14] and that model is necessarily not reality itself; all displays of information 


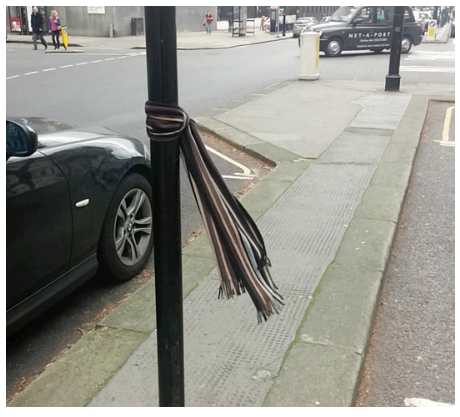

Figure 4: It's easy to imagine the feel of the wind on ourselves when we watch this scarf tied around a lamp post flapping in the breeze.

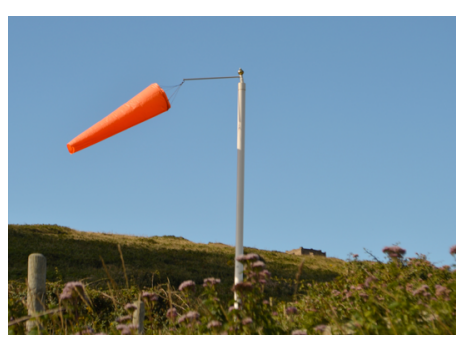

Figure 5: A windsock gives us more sense of the wind's qualities than a numerical display. are representations of a simplified model of phenomena in the world. Levels of indexicality [32], drawing on Peirceian semiology, are relevant here, addressing the "causal distance" between the phenomenon and how it is displayed. One advantage of interfaces seeking to provide a qualitative display is that they have the potential to enable the preservation of at least some of the complexity of real phenomena-representing complexity without attenuating variety [2]-even if we do not pay attention to it until we actually need to, in much the same way as certain phenomena in the rea world become salient only when we need to deal with them. Looking out of the window or opening the door to see and feel and hear what the weather is like outside presents us with complex phenomena, but we are able to interpret what actions we need to take, in a more experientially salient way than looking at some numbers on a weather app. The feel of the wind on our skin, or watching the wind affect the environment, gives us a better sense of whether we need a scarf or coat than knowing the quantitative value of the wind speed and direction (Figures 3, 4 and 5). We can see, hear and feel not just wind speed and direction, but other qualities of it-is it continuous? in short gusts? damp, dry? Qualitative displays could enable us to learn to recognize patterns in the world (and in data sets), and the characteristics of state changes, similarly to benefits identified in sonification research [35]. We should consider that 'qualitative' does not simply imply the absence of numbers. The examples we use in this paper might involve elements that could easily be quantified (rain drops, ink in a pen) but are given meaning through their display in a way that emphasises a quality or characteristic of the phenomenon. We recognise that this is potentially an ambiguous area, and are open to evolving the concept.

\section{A spectrum of one dimension of qualitative displays: directness of connection}

Table 1 shows a tentative spectrum of one dimension of qualitative displays, relating phenomena to the display in terms of how directly they are connected. Levels 0-1 involve direct use of a real-world phenomenon in the display; from about Level 2 up to Level 5, they involve increasing degrees of translation or transduction of the phenomena. This parallels ideas in indexical visualisation [32] and embedded data representation [41] in terms of 'situatedness' or causal distance to phenomena. Boundaries between levels here are dependent on observers' interpretations of what is signified (whether an effect is accidental or deliberate is a common question in design (teleonomy [25])).

Nevertheless, this spectrum permits a classification of some examples (Figures 6 and 7) and is being applied by the authors in undergraduate design studio projects. We note the absence of screen-based examples: this is not intentional, and we welcome adding relevant examples. There are many intersecting research areas we aim to explore; in current HCI research, the most relevant are data physicalisation, embedded data representation, tangible interaction, sonification, and glanceable displays. The work of Yvonne Jansen, Pierre Dragicevic and others [20] in data physicalisation, including compilation of examples

(http://dataphys.org/list), and embedded data

representation [41], provides us with many instances of qualitative display, mostly at what we are calling Levels 2-5 (Table 1); likewise, development of ubiquitous computing, tangible interaction and tangible user interfaces [39, 18, 17] and Hiroshi Ishii's subsequent vision of tangible bits [19] offers a huge set of projects, many of which provide qualitative interfaces for data or system interaction (usually at Levels 4-5; Table 1 ). 


\section{A spectrum of qualitative displays}

Relating phenomena to the display in terms of how directly they are connected:

Level 0: The phenomenon itself 'creates' the display directly

Level 1: The display is an 'accidental' sideeffect of the phenomenon

Level 2: The side-effect is 'incorporated' into a display that gives it meaning

Level 3: The display is a designed sideeffect of the phenomenon

Level 4: Some minor processing of the phenomenon creates the display

Level 5: Major processing of the phenomenon creates the display

Table 1: A spectrum of one dimension of qualitative displays

\section{Level 0:}

The phenomenon itself 'creates' the display directly

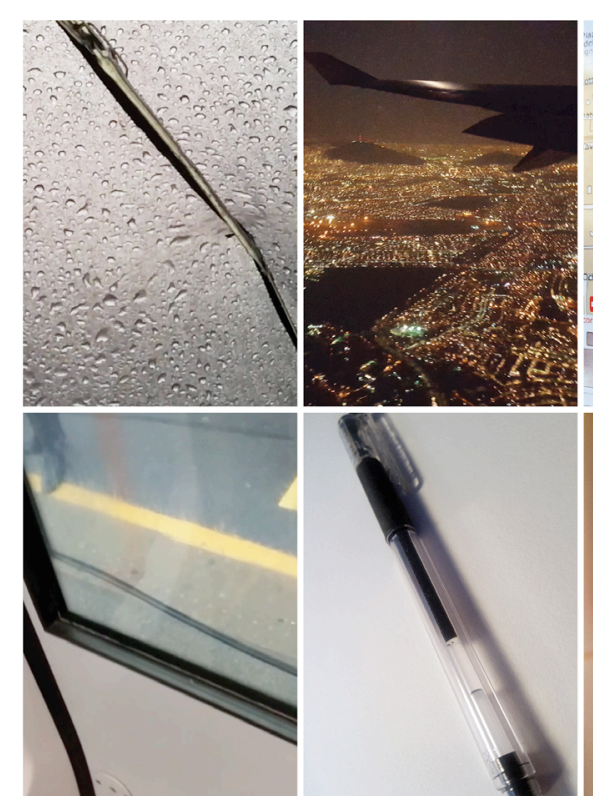

Level 1:

The display is an 'accidental' side-effect of the phenomenon

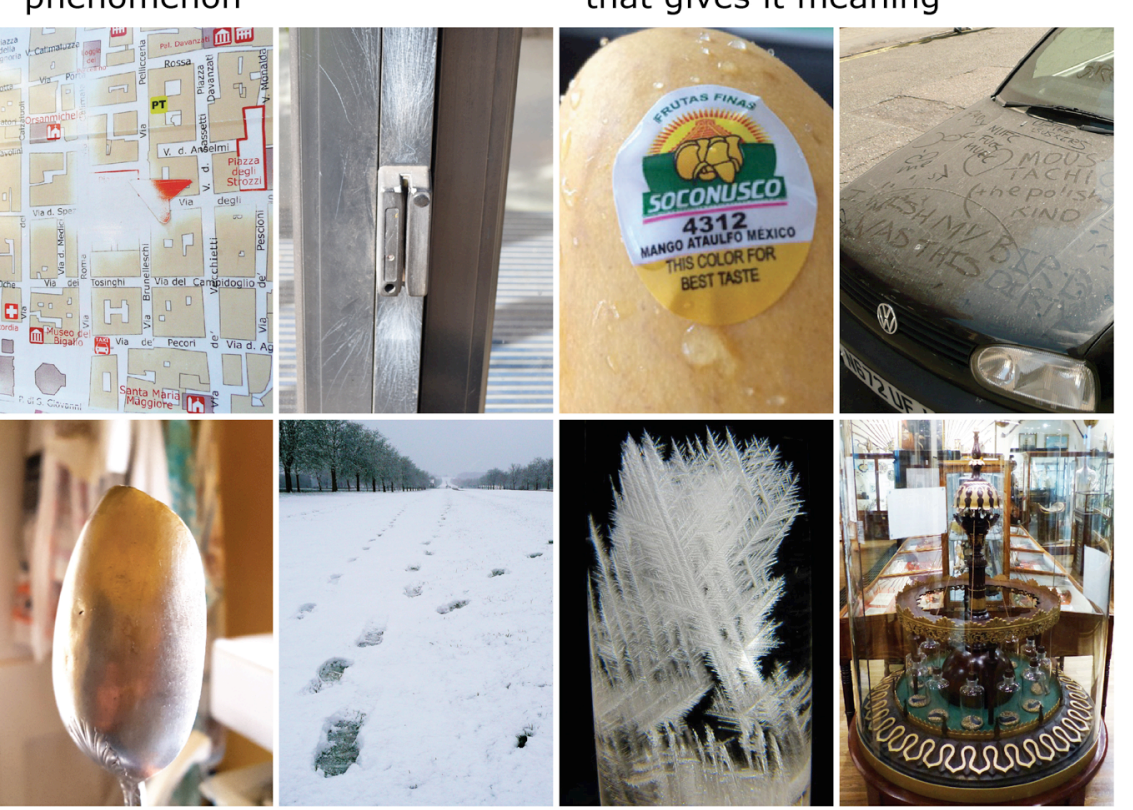

Figure 6: Some examples of displays from Levels 0, 1 and 2. Level 0: The pattern of raindrops hitting a translucent umbrellafrequency, coverage, and sound-directly creates a 'rain display' for the user, providing insight into the current state and enabling decisions about whether the umbrella is still needed; City lights create a display showing the shape of the city's districts and indicator of population density; Water trapped in a train carriage window moves as the train ac-/de-celerates, creating a dynamic display of the train's motion; A transparent pen is a physical progress bar for the amount of ink remaining-it could be quantified, but it is perhaps the quality of being not-yet-run-out which matters to the user. Level 1: A worn patch on a map accidentally provides a display of 'you are here'; Use marks [5] from previous users demonstrate how to use a swipe-card for entry to a building; A spoon worn through decades of use is an accidental display of the way in which it has been used [31]; Footprints in the snow 'accidentally' provide a display of previous walkers' paths. Level 2: 'This Color For Best Taste' label gives 'meaning' to the colour of a mango's skin for the consumer (Photo used with permission of Reddit user /u/cwm2355); Writing 'Clean Me' or other messages in dust on a car gives meaning to the dusty property; Admiral Robert Fitzroy's Storm Glass, as used on the voyage of the Beagle (1831-6), incorporates crystals whose changing appearance was believed to enable weather forecasting (Photo: ReneBNRW, Wikimedia Commons, public domain dedication); George Merryweather's Tempest Prognosticator (1851[30]) incorporates "a jury of philosophical councillors", 12 leeches whose movement on detecting an approaching storm causes a bell to ring (Photo: Badobadop, Wikimedia Commons, CC-BY-SA). 


\section{Level 3:}

The display is a designed

side-effect of the

phenomenon
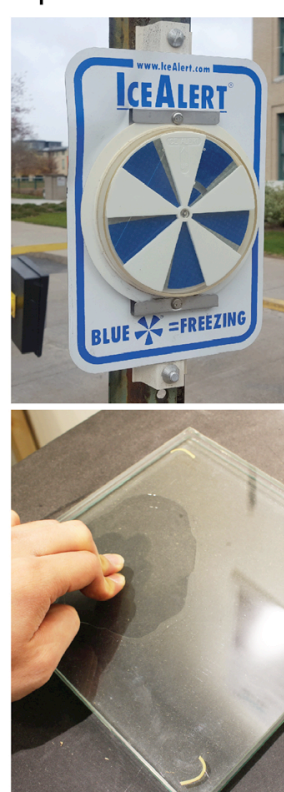
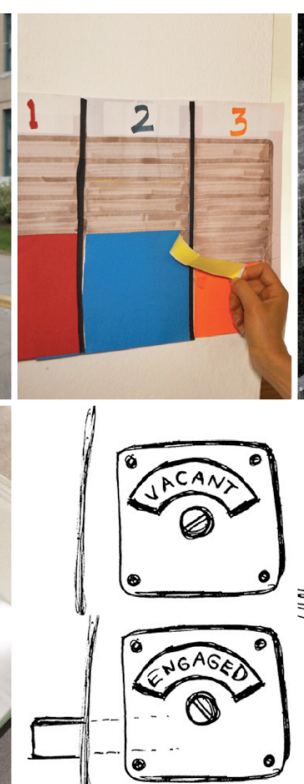

\section{Level 4:}

Some minor processing of the phenomenon creates the display

\section{Level 5:}

Major processing of the phenomenon creates the display

Figure 7: Some examples of displays from Levels 3,4 and 5. Level 3: IceAlert is designed so that freezing temperatures cause the blue reflectors to rotate to become visible; A 'participatory bar chart' by Dan Lockton along the lines of [22, 33, 16], designed so that 'voting' increases the visible height of the bar, though the votes are not numbered; A non-numerical weighing scale by Chang Hee Lee designed so liquid trapped under glass changes shape; Toilet stall door lock designed so display rotates from 'Vacant' to 'Engaged'-the position of the lock itself gives us a display of actionable information. Level 4: Chronocyclegraphs (1917) by Frank and Lillian Gilbreth, tracing manual workers' movements [10] (Photo from [15], Archive.org, out of copyright]; Live Wire (Dangling String) by Natalie Jeremijenko (1995)[39] moved a wire in proportion to local network traffic; Melbourne Mussel Choir, also by Natalie Jeremijenko with Carbon Arts [6] uses mussels with Hall effect sensors to translate the opening and closing of their shells into music; Availabot (2006), by Schulze \& Webb, later BERG [3], is a USB puppet which "stands to attention when your chat buddy comes online". Level 5:

Powerchord by Dan Lockton [29] provides real-time sonification of electricity use, translating it into birdsong or other ambient sound Immaterials: Ghost in the Field by Timo Arnall [1] visualizes "the three-dimensional physical space in which an RFID tag and a reader can interact with each other"; Ritual Machine 2 by the Family Rituals 2.0 project [23] uses patterns on a flip-dot display to visualize the countdown to a shared event for two people; Tempescope by Ken Kawamoto [21] visualizes weather conditions elsewhere in the world through re-creating them in a tabletop display (Photo used from Tempescope Press Kit). 


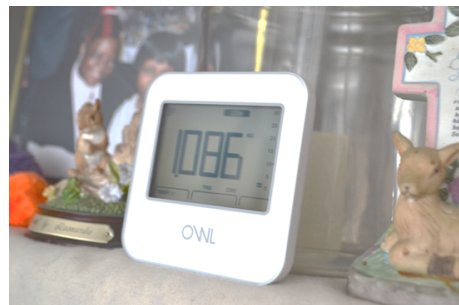

Figure 8: A quantitative electricity display that was used 'qualitatively' by a householder (see text).

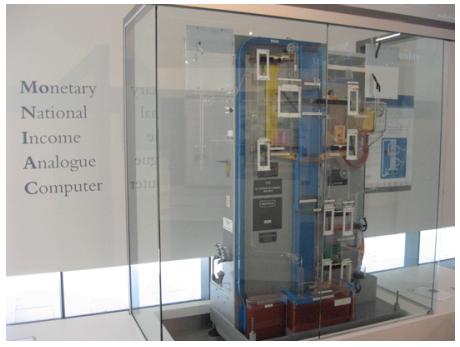

Figure 9: An example of MONIAC, the Phillips Machine, at the Reserve Bank of New Zealand (Photo by Kaihsu Tai, Wikimedia Commons, public domain dedication).
Sonification [35] and glanceable displays [e.g. 9, 34] also offer us diverse sets of examples often using nonnumerical representation, also largely at levels 4-5. As noted earlier, qualitative does not just mean nonquantitative, and the boundaries may be blurred: if a sonification directly maps numerical values to tones, is it much different to an unlabelled line chart? Or are sparklines [37], for example, a way of turning quantitative data into a form of qualitative presentation? Even with a quantitative display, how a person interprets it may have a qualitative dimension Figure 8 shows an electricity monitor used by a study participant [28] who accidentally set it to display $k g$ $\mathrm{CO}_{2}$ /day equivalent; this "meant nothing" to her but she interpreted the display such that " $>1$ " meant "expensive". 'Annotations' of values as users construct their own meaning [11] may fit here; the aim must however, be to avoid the kind of reductive 'qualitative' nature of a limited set of labels [13]. Analogy and metaphor are important here, and the almost-forgotten field of Analogue Computing offers us an intriguing perspective. By "build[ing] models that created a mapping between two physical phenomena" [7], some analogue computers effectively operated as 'direct' displays of an analogue of the 'original' phenomenon-a kind of meta-level 2 type qualitative display, with devices such as the 1949 Phillips Machine [4] (Figure 9), which performed operations on flows of coloured water to model the economy of a country, enabling an interactive visualization of a system in operation as it operates (there are parallels with Bret Victor and Nicky Case's work on explorable explanations [38, 8], and the development of visual programming languages).

Other areas of pertinent research and inspiration, are synaesthesia and mental imagery: sensory overlaps, fusions and mappings offer a fertile field for exploring qualitative displays of phenomena.

\section{Conclusion: What use is all of this?}

We are interested in using qualitative displays and interfaces for supporting decision-making, behaviour change and new practices through enabling new forms of understanding-as an aid to help people explore their own and each other's thinking, and specifically to help people understand their relationships and agency with the systems around them [26]. Projects using qualitative displays are unlikely simply to be dequantified 'conversion' of existing numerical displays; instead, the aim will be to make use of the approach to represent and translate phenomena appropriately, in ways which enable users to construct meaning and afford new ways of understanding, enabling nuance and avoiding reductiveness. The spectrum of the 'directness' dimension introduced here provides a possible starting point for this work, by giving a framework for analysing examples and suggesting ways of handling phenomena to be displayed, and is currently being used by the authors to brief an undergraduate design studio project on materialising environmental phenomena to reveal hidden relationships. We welcome the opportunity to learn from the $\mathrm{CHI}$ community to inform our future explorations of this area.

\section{Acknowledgements}

Thanks to Dr Delfina Fantini van Ditmar, Dr Laura Ferrarello, Flora Bowden, Gyorgyi Galik, Stacie Rohrbach, Ross Atkin, Shruti Grover, Veronica Ranner and Dixon Lo for discussions formulating some of these ideas was explored, and to the reviewers. Unless otherwise noted, photos are by the authors. 


\section{References}

1. Timo Arnall. 2014. Exploring 'immaterials': Mediating design's invisible materials. International Journal of Design 8, 2: 101-117.

http://www.ijdesign.org/ojs/index.php/IJDesign/art icle/view/1408

2. W. Ross Ashby. 1956. An Introduction to Cybernetics. Chapman \& Hall, London.

3. BERG. 2008. Availabot. Retrieved Jan 10, 2017 from http://berglondon.com/projects/availabot/

4. Chris Bissell. 2007. The Moniac: A Hydromechanical Analog Computer of the 1950s. IEEE Control Systems Magazine 27, 1:59-64. https://dx.doi.org/ 10.1109/MCS.2007.284511

5. Brian Burns. 2007. From Newness to Useness and Back Again: A review of the role of the user in sustainable product maintenance. Retrieved June 1 , 2009 from http://extra.shu.ac.uk/productlife/ Maintaining \%20Products $\% 20$ presentations/Brian $\%$ 20Burns.pdf

6. Carbon Arts. 2013. Melbourne Mussel Choir Retrieved Jan 10, 2017 from

http://www.carbonarts.org/projects/melbournemussel-choir/

7. Charles Care. 2006-7. A Chronology of Analogue Computing. The Rutherford Journal 2. Retrieved Jan 10, 2017 from http://www. rutherford journal.org/article020106.htm

8. Nicky Case. 2014. Explorable Explanations. Blog post (Sept 8, 2014). Retrieved Jan 10, 2017 from http://blog.ncase.me/explorable-explanations/

9. Sunny Consolvo, Predrag Klasnja, David W. McDonald, Daniel Avrahami, Jon Froehlich, Louis LeGrand, Ryan Libby, Keith Mosher, and James A. Landay. 2008. Flowers or a Robot Army? Encouraging Awareness \& Activity with Personal, Mobile Displays. In Proceedings of 10th
International Conference on Ubiquitous Computing (UbiComp'08): 54-63. https://doi.org/10.1145/ 1409635.1409644

10. Régine Debatty. 2012. The Chronocyclegraph. Blog post, We Make Money Not Art (May 6. 2012). Retrieved Jan 102017 from http://we-makemoney-not-art.com/the_chronocyclegraph/

11. Paul Dourish. 2004. What we talk about when we talk about context. Personal and Ubiquitous Computing 8, 1: 19-30. http://dx.doi.org/10.1007/ s00779-003-0253-8

12. Chris Elsden, David Kirk, Mark Selby, and Chris Speed. 2015. Beyond Personal Informatics: Designing for Experiences with Data. In Proceedings of the SIGCHI Conference Extended Abstracts on Human Factors in Computing Systems (CHI EA '15): 2341-2344.

https://dx.doi.org/10.1145/2702613.2702632

13. Delfina Fantini van Ditmar and Dan Lockton. 2016. Taking the Code for a Walk. Interactions 23, 1: 6871. https://dx.doi.org/10.1145/2855958

14. Heinz von Foerster. 1973. On constructing a reality. In F.E. Preiser (Ed.). Environmental Design Research Vol. 2. Dowden, Hutchinson \& Ross, Stroudberg: 35-46. Reprinted in Heinz von Foerster. 2003. Understanding Understanding Essays on Cybernetics and Cognition. SpringerVerlag, New York: 211-228.

https://dx.doi.org/10.1007/0-387-21722-3_8

15. Frank Gilbreth and Lillian Gilbreth. 1917. Applied Motion Study: a collection of papers on the efficient method to industrial preparedness. Sturgis \& Walton, New York. Retrieved Jan 10, 2017 from https://archive.org/details/appliedmotionstu00gilbri ch

16. Hans Haacke. 2009. Lessons Learned. Tate Papers 12. Retrieved Jan 10, 2017 from

http://www.tate.org.uk/download/file/fid/7265 
17. Eva Hornecker and Jacob Buur. 2006. Getting a grip on tangible interaction: a framework on physical space and social interaction. In Proceedings of the SIGCHI Conference on Human Factors in Computing Systems (CHI '06): 437-446. https://dx.doi.org/10.1145/1124772.1124838

18. Hiroshi Ishii and Brygg Ullmer. 1997. Tangible bits: towards seamless interfaces between people, bits and atoms. In Proceedings of the SIGCHI Conference on Human Factors in Computing Systems (CHI '97): 234-241. https://dx.doi.org/ $10.1145 / 258549.258715$

19. Hiroshi Ishii, Dávid Lakatos, Leonardo Bonanni, Jean-Baptiste Labrune. 2012. Radical atoms: beyond tangible bits, toward transformable materials. Interactions 19, 1: 38-51. https://dx.doi.org/10.1145/2065327.2065337

20. Yvonne Jansen, Pierre Dragicevic, Petra Isenberg, Jason Alexander, Abhijit Karnik, Johan Kildal, Sriram Subramanian, and Kasper Hornbæk. 2015. Opportunities and Challenges for Data

Physicalization. In Proceedings of the SIGCHI Conference on Human Factors in Computing Systems (CHI '15): 3227-3236. https://dx.doi.org/ $10.1145 / 2702123.2702180$

21. Ken Kawamoto. 2012. Prototyping "Tempescope", an ambient weather display. Blog post (Nov 15 2012). Retrieved Jan 10, 2017 from http://kawalabo.blogspot.jp/2012/11/prototypingtempescope-ambient-weather.html

22. Lucy Kimbell. 2011. Physical Bar Charts. Retrieved Jan 10, 2017 from http://www.lucykimbell.com/ LucyKimbell/PhysicalBarCharts. htm

23. David Kirk, David Chatting, Paulina Yurman, and Jo-Anne Bichard. 2016. Ritual Machines I \& II: Making Technology at Home. In Proceedings of the SIGCHI Conference on Human Factors in Computing Systems (CHI '16): 2474-2486. http://dx.doi.org/10.1145/2858036.2858424
24. Ian Li, Anind Dey, and Jodi Forlizzi. 2010. A stagebased model of personal informatics systems. In Proceedings of the SIGCHI Conference on Human Factors in Computing Systems (CHI '10): 557-566 https://dx.doi.org/10.1145/1753326.1753409

25. Dan Lockton. 2012. POSIWID and Determinism in Design for Behaviour Change. Social Science Research Network. http://dx.doi.org/10.2139/ ssrn. 2033231

26. Dan Lockton. 2016. Designing Agency in the City. In Lacey Pipkin (Ed.), The Pursuit of Legible Policy: Agency and Participation in the Complex Systems of the Contemporary Megalopolis. Buró-Buró Mexico City: 53-61. http://legiblepolicy.info/book/ Legible-Policies_BB.pdf

27. Dan Lockton, David Harrison, and Neville Stanton. 2010. The Design with Intent Method: A design tool for influencing user behaviour. Applied Ergonomics 41, 3: 382-392. http://dx.doi.org/10.1016/ j.apergo.2009.09.001

28. Dan Lockton, Flora Bowden, Catherine Greene, Clare Brass, and Rama Gheerawo. 2013. People and energy: A design-led approach to

understanding everyday energy use behaviour. In Proceedings of EPIC 2013: Ethnographic Praxis in Industry Conference: 348-362. https://dx.doi.org/ 10.1111/j.1559-8918.2013.00029.x

29. Dan Lockton, Flora Bowden, Clare Brass, and Rama Gheerawo. 2014. Powerchord: Towards ambient appliance-level electricity use feedback through real-time sonification. In Proceedings of UCAmI 2014: 8th International Conference on Ubiquitous Computing \& Ambient Intelligence: 48-51.

https://dx.doi.org/10.1007/978-3-319-13102-3_10

30. George Merryweather. 1851. An essay explanatory of the Tempest Prognosticator in the building of the Great Exhibition for the Works of Industry of All Nations. John Churchill, London. Retrieved Jan 10 2017 from https://archive.org/details/b2804163x 
31. Bruno Munari. 1971. Design as Art (trans. Patrick Creagh). Pelican Books, London.

32. Dietmar Offenhuber and Orkan Telhan. 2015. Indexical Visualization-the Data-Less Information Display. In Ulrik Ekman, Jay David Bolter, Lily Diaz, Morten Søndergaard, and Maria Engberg (eds.). Ubiquitous Computing, Complexity and Culture: 288-303. Routledge, New York.

33. Jennifer Payne, Jason Johnson, and Tony Tang. 2015. Exploring Physical Visualization. In Jason Alexander, Yvonne Jansen, Kasper Hornbæk, Johan Kildal and Abhijit Karnik. Exploring the Challenges of Making Data Physical. Proceedings of the SIGCHI Conference Extended Abstracts on Human Factors in Computing Systems (CHI EA '15):

http://hcitang.org/papers/2015-chi2015workshopphysvis.pdf

34. Tim Regan, David Sweeney, John Helmes, Vasillis Vlachokyriakos, Siân Lindley, and Alex Taylor. 2015. Designing Engaging Data in Communities. In Proceedings of the SIGCHI Conference Extended Abstracts on Human Factors in Computing Systems (CHI EA '15): 271-274. http://dx.doi.org/ $10.1145 / 2702613.2725432$

35. Stefania Serafin, Karmen Franinovic, Thomas Hermann, Guillaume Lemaitre, Michal Rinott, and Davide Rocchesso. 2011. Sonic Interaction Design. In Thomas Hermann, Andy Hunt, and John Neuhoff (Eds.), The Sonification Handbook. Logos, Berlin: 87-110. http://sonification.de/handbook/ index.php/chapters/chapter5/

36. Melanie Swan. 2013. The quantified self: fundamental disruption in big data science and biological discovery. Big Data 1, 2: 85-99. https://dx.doi.org/10.1089/big.2012.0002

37. Edward Tufte. 2001. The Visual Display of Quantitative Information ( $2^{\text {nd }}$ ed.). Graphics Press, Cheshire, CT.
38. Bret Victor. 2011. Explorable Explanations. March 10, 2011. Retrieved Jan 10, 2017 from http://worrydream.com/ ExplorableExplanations

39. Mark Weiser and John Seely Brown. 1995. Designing Calm Technology. Dec 21, 1995. Retrieved Jan 10, 2017 from http://www.ubiq.com/ weiser/calmtech/calmtech.htm

40. Sherri C. Widen. 2013. Children's Interpretation of Facial Expressions: The Long Path from ValenceBased to Specific Discrete Categories. Emotion Review 5, 1: 72-77. https://dx.doi.org/10.1177/ 1754073912451492

41. Wesley Willett, Yvonne Jansen, and Pierre Dragicevic. 2017. Embedded Data Representations. IEEE Transactions on Visualization and Computer Graphics 23, 1: 461-470. https://dx.doi.org/10.1109/TVCG.2016.2598608

42. Gary Wolf. 2010. The quantified self. Video (June 2010). Retrieved Jan 10, 2017, from https://www.ted.com/talks/gary_wolf_the_quantifi ed_self 